\title{
A Case Report of Giant Cell Rich Osteosarcoma
}

\section{Fathi Afshin ${ }^{1}$, Maskani Reza ${ }^{1 *}$ and Hosseini Anbaran Sonia ${ }^{2}$}

${ }^{1}$ Pediatric Department, Bouali Children's Hospital, Ardabil University of Medical Sciences (ARUMS), Iran

${ }^{2}$ Department of Medical, Ardabil Branch, Ardabil University of Medical Sciences (ARUMS), Iran

*Corresponding Author: Maskani Reza, Pediatric Department, Bouali Children's Hospital, Ardabil University of Medical Sciences (ARUMS), Iran.

Received: October 11, 2019; Published: November 04, 2019

DOI: $10.31080 /$ ASPE.2019.02.0177

\begin{abstract}
Giant cell tumor of bone (GCTB) is a benign but locally aggressive bone tumor of young adults. It typically presents as a large lytic mass at the end of the epiphysis of long bones. Grossly it is comprised of cystic and hemorrhagic areas with little or no periosteal reaction (1) Giant cell tumor of talus is a rare entity. In contrast to GCT of long bones, most cases occur in a younger age group and tend to be multicentric (2) we report one case of giant cell rich osteosarcoma of talus bone in a 11 years old Iranian girl in December 2017 that presented with tenderness of the left ankle after a minor trauma with a tumoral lesion in Tc99m-MDP scan. Biopsy of talus lesion reported a giant cell tumor with focal atypical chondroid and osteoid differentiation highly suggestive of a low grade giant cell rich osteosarcoma. Neoadjuvant chemotherapy with cisplatin 80mg and Adriamycin 50mg was begin for her.
\end{abstract}

Keywords: Giant Cell Tumor; Bone; Osteosarcoma

\section{Introduction}

The giant cell tumor of bone (GCTB) is a benign but locally aggressive bone tumor of young adults of 20-40 years of age. It constitutes about $4-5 \%$ of all bone tumors and about $18 \%$ of all benign bone tumors. It is slightly more common in females [1] Radiologically, it is usually lytic and expansile without prominent peripheral sclerosis and periosteal reaction. Some pathologists consider it a low grade or potentially malignant neoplasm. The tumor is locally aggressive and destructive, and it tends to recur after simple curetting [1]. GCTB is generally considered a true neoplastic condition with well-defined clinical, radiological and histopathological features $[3,4]$ Giant cell tumor of talus is a rare entity. In contrast to GCT of long bones, most cases occur in a younger age group and tend to be multicentric [2].

\section{Case Presentation}

A 11-year-old girl presented in December 2016 with one-month history of left ankle pain after a minor trauma. Radiographs from an outside institution showed a cystic lesion in the left ankle (Figure 1). Ankle MRI reported a homogenous well-defined speculated cystic mass measuring $25 * 15 \mathrm{~mm}$ in posterior site of talus with narrow trainsitional zone. Mild joint effusion and soft tissue edema are noted (Figure 2) The patient was undergoing surgery and histopathology report of the lesion was suggestive for solitary bone cyst with reparative changes following fracture. 3 months after surgery the patient's symptoms returned again.in new radiographies showed a cystic lesion in the left ankle (Figure 1).

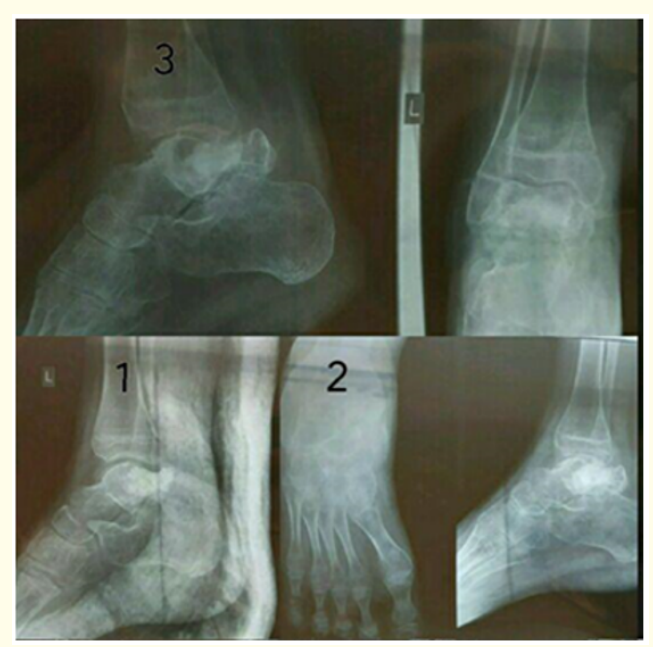

Figure 1 


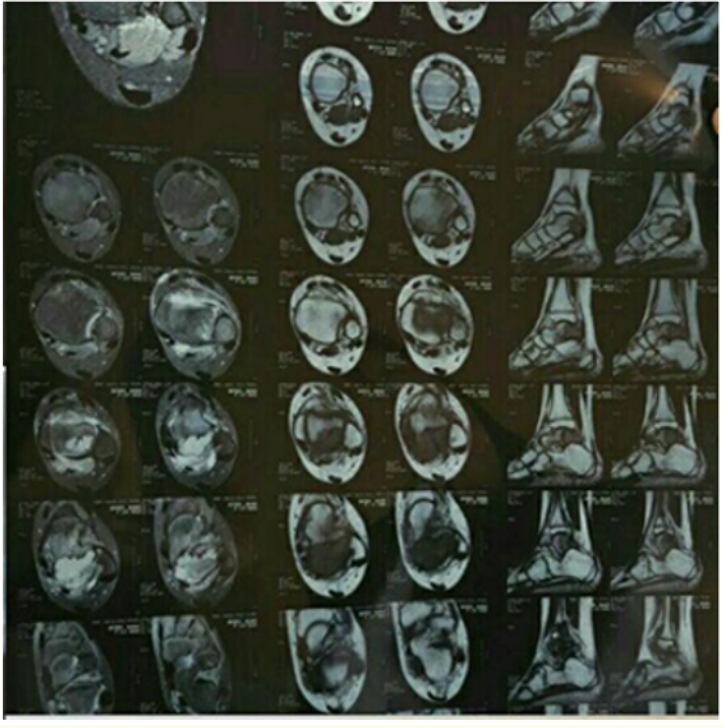

Figure 2

New MRI reported lateral superior part of talus is dark due to previous surgery, metallic artifact and sement application. Enhanced distal tibia and talus body and proximal calcaneum are seen as osteitis but no suggestive tumoral tissue is seen (Figure 3).

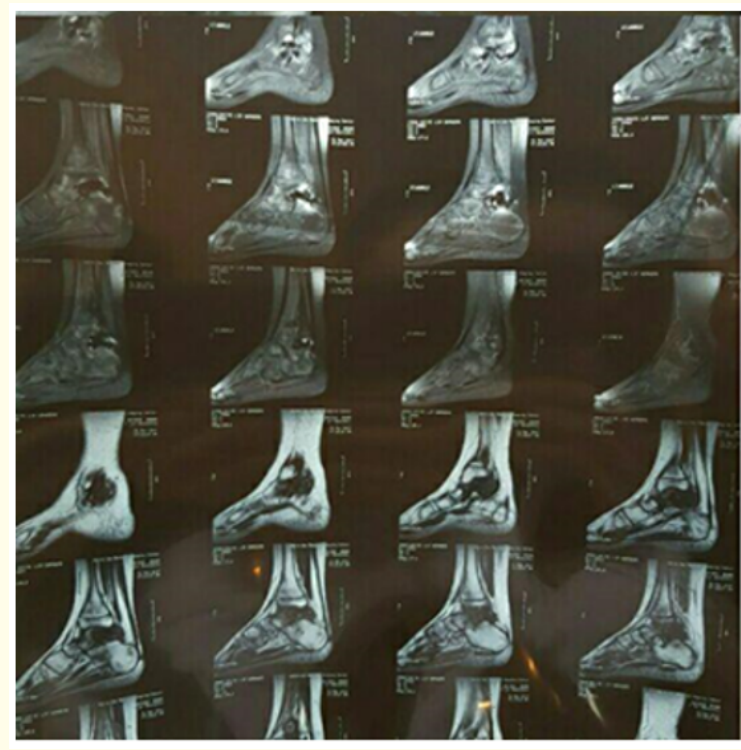

Figure 3

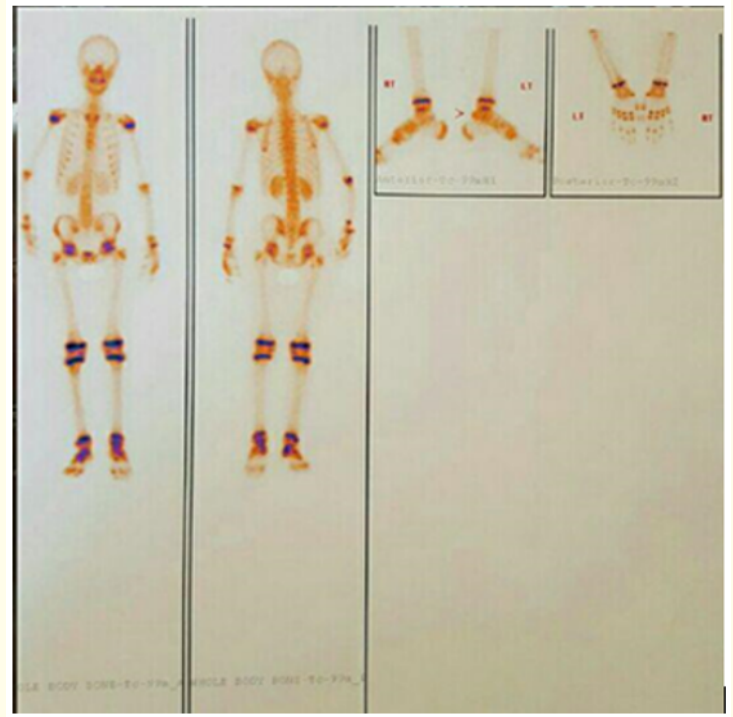

Figure 4

After that whole body scan with injection of the $20 \mathrm{mCi}$ Tc $99 \mathrm{~m}$ MDP for patient Was requested and the report was this: the scan finding is suggestive of tumoral lesion in the posterior process of left talus. Increased uptake in the trochlea and neck of left talus can be due to surgical manipulation or extension of tumor. New pathology reported Giant cell tumor with focal atypical chondroid and osteoid differentiation highly suggestive of a low grade giant cell rich osteosarcoma, pending clinico-pathologic and radiologic correlation. Finally giant cell osteosarcoma was diagnosed for patient and neoadjuvant chemotherapy with cisplatin $80 \mathrm{mg}$ and Adriamycin $50 \mathrm{mg}$ was begin for her last radiography is showed in (Figure 1).

\section{Discussion}

Giant cell-rich osteosarcoma is a rarer variant that has very close resemblance to giant cell tumour. Patients usually present nonspecific symptoms of pain and palpable mass. It usually shows an osteolytic lesion with locally spared new bone formation in the metaphysis and/or metaepiphysis on imaging. Histologically, the atypical tumour cells with osteoid formation and multinucleated giant cells are the key factor in the diagnosis and differential diagnosis [5]. Giant cell rich osteosarcomas, histological variant of conventional osteosarcomas account for $3 \%$ of all cases of osteosarcomas and most of them are arise from the appendicular skel- 
eton [6]. Giant cell-rich osteosarcomas are sometimes difficult to distinguish from giant cell tumors by age, location, magnetic resonance imaging findings, and pathology. Radiography may be useful in the diagnosis of giant cell-rich osteosarcoma [7]. Malignant giant cell tumor of bone has become a confusing term because of the inclusion of many giant cell-rich sarcomas not related to giant cell tumor of bone (GCT) The term "malignancy in giant cell tumor" may overcome this problem in semantics Malignancy in GCT can be classified as primary when it arises in juxtaposition to a benign giant cell tumor (synchronous malignancy) or secondary when it arises at the site of a previously treated GCT (secondary metachronous malignancy). Most malignancies in GCT are secondary, usually after previous radiation therapy and less commonly after a latent period and previous curettage [8]. In our case, the radiological fining presenting an osteolytic lesion that the scan finding is suggestive of tumoral lesion and highly suggestive of a low grade giant cell rich osteosarcoma. Chest radiography reported no mass lesion and mediastinum, heart shadow size and shape, bone and ribs were normal and patient will be follow after 3 week for second chemotherapy session.

\section{Bibliography}

1. Haque AU and Moatasim A. "Giant cell tumor of bone: a neoplasm or a reactive condition?" International Journal of Clinical and Experimental Pathology 1 (2008): 489-501.

2. Siddhartha Sharma., et al. "Giant cell tumor of talus: a case report”. Cases Journal 2 (2009): 74.

3. Werner M. "Giant cell tumour of bone: morphological, biological and histogenetical aspects". International Orthopaedics 30 (2006): 484-489.

4. Zheng MH., et al. "The histogenesis of giant cell tumour of bone: a model of interaction between neoplastic cells and osteoclasts". Histology and Histopathology 16 (2001): 297-307.

5. Cheng-Sheng Wang., et al. "Giant cell-rich osteosarcoma in long bones: clinical, radiological and pathological features". 118.8 (2013): 1324-1334.

6. Verma RK Gupta G., et al. "Primary giant cell rich osteosarcoma of maxilla: an unusual case report". Journal of Oral and Maxillofacial Surgery 10 (2011): 159-162.
7. Nagata S., et al. "Giant cell-rich osteosarcoma of the distal femur: radiographic and magnetic resonance imaging findings". Radiation Medicine 24 (2006): 228-232.

8. Bertoni F., et al. "Malignancy in giant cell tumor". Skeletal Radiology 32 (2003): 143-146.

Volume 2 Issue 12 December 2019 (C) All rights are reserved by Maskani Reza. 